\title{
High purity FAU-type zeolite catalysts from shale rock for biodiesel production
}

1. Division of Chemistry and Environmental Science, Manchester Metropolitan University, Chester St., Manchester, M1 5GD, United Kingdom. email: a.m.doyle@mmu.ac.uk

2. Department of Biochemical Engineering, Al-Khwarizmi College of Engineering, University of Baghdad, Al-Jadryah, P.O. Box 47008, Baghdad, Iraq. email: ziadalismaeel@yahoo.com.

3. Department of Chemical Engineering, University of Technology, 52 Alsinaa St., PO Box 35010, Baghdad, Iraq. email: talib_albyati@yahoo.com.

4. Department of Chemical Engineering, College of Engineering, University of Baghdad, AlJadryah, P.O. Box 47221, Baghdad, Iraq. email: dr_ammar19@yahoo.com.

* Corresponding author: a.m.doyle@mmu.ac.uk

\section{Abstract}

FAU-type zeolite was prepared using Irish shale rock and tested as a catalyst in the liquidphase esterification of oleic acid (a model test reaction for biodiesel production). A systematic study was conducted (over the stated preparation ranges) by varying the water:shale ratio (4:1 to $15: 1$ by mass), and mixing (1-24 h), aging (6-48 h) and hydrothermal treatment times (6-72 h) to determine the optimal parameters. XRD confirmed that the product purity was highly dependent on the experimental conditions used. The BET surface area of the calcined FAUtype zeolite was $571 \mathrm{~m}^{2} \mathrm{~g}^{-1}$ and its crystal purity was comparable to that of a commercial zeolite Y. The prepared zeolite was catalytically active in the esterification of oleic acid with ethanol reaching a maximum of $78 \%$ conversion after 90 mins, which is practically identical to that recorded for commercial zeolite $\mathrm{Y}$.

Keywords; Biodiesel, esterification, Y zeolite, FAU, shale

\section{Introduction}

The need for a reliable supply of fuel is increasing due to growing human population and expanding economies in both developing and developed countries. One innovation that addresses this requirement is fracking, which allows previously unattainable oil and gas 
reserves to be extracted from deep beneath the Earth's surface [1]. This typically occurs in shale rock, which is a sedimentary rock composed of a mixture of clay minerals formed by deposition of particulates and organic matter. Shale can be removed at shallower levels by open pit mining and, thereafter, the oil is separated from the shale by pyrolysis at high temperature. The vast majority of what remains is oil shale ash, which may be used for soil treatment and cement production, but millions of tonnes are added to landfill annually with associated costs. Efforts have been made, therefore, to use shale as a cheap and widely available starting material to generate value-added products. Shale is also found in areas without containing fossil fuels. Collectively, these regions contain huge reserves of shale rock that lie at/immediately below the surface and are, therefore, easily accessible and an (almost) limitless supply of starting materials for further synthesis.

Zeolite are high surface area materials that have been widely used in areas such as water treatment and purification, humidity control, and heterogeneous catalysis [2]. To date, the majority of established syntheses have used artificial reagents by heating a solution of some form of silica, alumina and alkylammounium salts in water, which over time forms a solid precipitated aluminosilicate zeolite [3]. Zeolites may also be prepared from naturally occurring reagents. Clays, rocks and ash residues from combustion of solid fuels contain large amounts of oxygen, silicon and aluminium that have similar chemical compositions to those of some aluminosilicate zeolites. Fly-ash, for example, is produced in coal-fired power plants and has been used to prepare zeolites, albeit initially with low crystal purity [4-10]; the purity was improved by employing the alkali fusion method [11-14]. Kaolin, a naturally occurring mineral, has been well studied as a starting material for zeolite synthesis and, to date, a wide range of different zeolite types have been prepared [15-25]. In a recent paper, fly ash-kaolinite mixtures were used to synthesise zeolites at low temperature [26]. We recently reported the successful preparation of zeolite $\mathrm{Y}$ from kaolin; the prepared material demonstrated structural characteristics comparable to those of a commercial zeolite and was a highly active catalyst in the esterification of oleic acid [27]. The (trans)esterification of natural oils to produce biodiesel is well known, and a number of reviews have been published on the use of zeolite catalysts in biodiesel production [28-33 and references therein]. Oil shale ash has been used to prepare zeolite types in impure form; A, which was used to remove heavy metals from aqueous solution [34,35], PI [36,37], hydroxysodalite [38] and a composite structure containing types A, X and hydroxysodalite [39]. 
Here, we show that surface shale rock from Ireland is an excellent reagent to prepare faujasite (FAU-type zeolite). The zeolite characteristics are found to be very dependent on the choice of experimental conditions. The method developed here gives FAU-type zeolite in pure form, which is an improvement on the mixed phase materials and high quantities of quartz impurity previously reported [34-39]. The prepared zeolite is an active catalyst in the esterification of oleic acid, an important model reaction for biodiesel production, with near identical catalytic properties to those of a commercial zeolite Y.

\section{Experimental}

\subsection{Materials}

The following is a list of the materials' source/supplier and purity; shale rock was collected from the surface of a recently tilled field on a working farm in county Wexford, Ireland, washed with water to remove all soil residue and dried at $120{ }^{\circ} \mathrm{C}$ for three hours; sodium hydroxide $(\mathrm{NaOH})$ pellets, extra pure, Scharlau; sodium silicate $\left(\mathrm{Na}_{4} \mathrm{SiO}_{4}\right), 99 \%$ purity, BDH Chemicals Ltd.; ammonium chloride $\left(\mathrm{NH}_{4} \mathrm{Cl}\right)$, Sigma Aldrich; absolute ethanol $\left(\mathrm{C}_{2} \mathrm{H}_{5} \mathrm{OH}\right)$ Sigma Aldrich; phenolphthalein, $2 \%$ in ethanol, Sigma-Aldrich. Commercial zeolite Y was purchased from Qingdao Wish Chemicals Co. Ltd.

\subsection{Zeolite preparation and optimisation}

The clean shale was crushed in a ball mill apparatus, sieved to $<90 \mu \mathrm{m}$ and calcined in air at $800{ }^{\circ} \mathrm{C}$ for $4 \mathrm{~h}$ to remove organic matter. $10 \mathrm{~g}$ of calcined shale was then refluxed with $40 \mathrm{~cm}^{3}$ of $5 \mathrm{M} \mathrm{HCl}$ at $85^{\circ} \mathrm{C}$ for $4 \mathrm{~h}$ (to remove $\mathrm{Fe}$ ) and the product recovered by filtration. 1 part (by mass) of calcined shale was mixed with 1.5 parts (by mass) of $40 \mathrm{wt} \%$ aqueous $\mathrm{NaOH}$ solution and the mixture was heated at $850^{\circ} \mathrm{C}$ in air for $3 \mathrm{~h}$ in a furnace to get fused shale. The fused shale was then crushed to powder form. Thereafter, varying amounts of fused shale and sodium silicate were added to distilled water in polypropylene bottles, mixed (stirred) at room temperature for $1 \mathrm{~h}$, aged under static conditions at room temperature for $24 \mathrm{~h}$, hydrothermally treated at $100{ }^{\circ} \mathrm{C}$ for $24 \mathrm{~h}$ and the product recovered by filtration. Unless where stated otherwise, this procedure was used to conduct a study to determine the influences of (in the following order): (a) water content: $2 \mathrm{~g}$ fused shale and $1 \mathrm{~g}$ sodium silicate were added to 8 , $12,16,20$ and $30 \mathrm{~g}$ distilled water to give water:fused shale ratios of 4:1, 6:1, 8:1, 10:1, 12:1 and 15:1; (b) mixing time: $1 \mathrm{~g}$ fused shale and $0.5 \mathrm{~g}$ sodium silicate were added to $8 \mathrm{~cm}^{3}$ of distilled water and mixed for 1, 3, 6, 12, 18 and $24 \mathrm{hrs;} \mathrm{(c)} \mathrm{aging} \mathrm{time} \mathrm{(under} \mathrm{static} \mathrm{conditions):}$ 
$1 \mathrm{~g}$ fused shale and $0.5 \mathrm{~g}$ sodium silicate were added to $8 \mathrm{~cm}^{3}$ of distilled water, mixed for 3 hrs and aged for 6, 12, 18, 24 and $48 \mathrm{hrs;}$ (d) hydrothermal treatment time: $1 \mathrm{~g}$ fused shale and $0.5 \mathrm{~g}$ sodium silicate were added to $8 \mathrm{~cm}^{3}$ of distilled water, mixed for $3 \mathrm{~h}$, aged for $18 \mathrm{~h}$ and hydrothermally treated at $100{ }^{\circ} \mathrm{C}$ for $6,12,18,24,48$ and $72 \mathrm{~h}$.

To convert the prepared zeolite from $\mathrm{Na}^{+}$to $\mathrm{NH}_{4}{ }^{+}$form, $90 \mathrm{~g}$ of zeolite were added to $250 \mathrm{~cm}^{3}$ of $2 \mathrm{~N}$ ammonium chloride and stirred in a round bottom flask at room temperature for $2 \mathrm{~h}$. The solid was recovered by filtration, washed with distilled water and the ion-exchange procedure was repeated a further two times using $60 \mathrm{~g}$ and $30 \mathrm{~g}$, respectively. The solid was again recovered by filtration, washed with distilled water, dried for $12 \mathrm{hrs}$ at $120{ }^{\circ} \mathrm{C}$ and calcined in air at $500{ }^{\circ} \mathrm{C}$ for $4 \mathrm{~h}$.

\subsection{Characterization}

X-Ray diffraction (XRD) was conducted in ambient conditions using a Panalytical X'Pert Powder diffractometer with $\mathrm{Cu} \mathrm{K} \alpha$ radiation $(\lambda=1.5406 \AA)$. All powder diffraction patterns were recorded from 4 to $50^{\circ} 2 \Theta$ with step size 0.026 and step time $50 \mathrm{~s}$, using an X-ray tube operated at $40 \mathrm{kV}$ and $30 \mathrm{~mA}$ with fixed $1 / 4^{\circ}$ anti-scatter slit. Nitrogen adsorption/desorption measurements were carried out using a Micromeritics ASAP 2020 Surface Analyser at -196 ${ }^{\circ} \mathrm{C}$. Samples were degassed under vacuum $\left(\mathrm{p}<10^{-5} \mathrm{mbar}\right.$ ) for $12 \mathrm{~h}$ at $350{ }^{\circ} \mathrm{C}$ prior to analysis. BET-surface areas of the samples were calculated in the relative pressure range 0.05-0.30. Microscopic images were recorded using a JEOL JSM-5600LV scanning electron microscope (SEM). Semi-quantitative chemical analysis was performed by energy-dispersive X-ray spectroscopy (EDAX) using a detector from Oxford Instruments.

\subsection{Catalyst testing}

The esterification reaction of oleic acid with ethanol was performed by reflux in a $500 \mathrm{ml}$ batch reactor placed in a thermostatic oil bath under stirring. The desired amount of catalyst was dried before reaction at $130{ }^{\circ} \mathrm{C}$ for $2 \mathrm{~h}$. The reactor was loaded with $50 \mathrm{ml}(44.75 \mathrm{~g})$ of oleic acid and the desired amount of pre-heated ethanol was then added to give an ethanol to oleic acid molar ratio of 6. Esterification was carried out at reaction temperatures 40, 50, 60 and 70 ${ }^{\circ} \mathrm{C}$. $5 \mathrm{ml}$ samples were withdrawn from the reaction mixture at 15 minute intervals, and centrifuged for $10 \mathrm{~min}$ at $3000 \mathrm{rpm}$ to separate the solid zeolite from the liquid phase. The supernatant layer was analysed by titration with $0.1 \mathrm{~N} \mathrm{KOH}$, using phenolphthalein indicator, to evaluate the acid value (AV) as shown in the following equation; 


$$
\mathrm{AV}=\frac{\mathrm{ml} \text { of } \mathrm{KOH} \times \mathrm{N} \times 56}{\text { Weight of Sample }}
$$

137 From the acid value, the conversion of oleic acid can be calculated for each amount of the 138 catalyst as shown in the following equation;

$$
\text { conversion } \%=\frac{\mathrm{AV}_{\mathrm{t} 0}-\mathrm{AV} \mathrm{t}}{\mathrm{AV_{ \textrm {t } 0 }}} \times 100 \%
$$

where:

$\mathrm{AV}_{\mathrm{t}}$ (acid value of the reaction product at time $\mathrm{t}$ )

\section{Results and Discussion}

\subsection{Removal of Fe and alkaline fusion}

The XRD patterns showing the effects of calcination, acid leaching and alkaline fusion are shown in Fig. 1. The untreated shale (dried at $120^{\circ} \mathrm{C}$ ) is composed primarily of chlorite, laumontite and quartz [34-39]. Calcination in air at $800{ }^{\circ} \mathrm{C}$ removes chlorite completely and causes partial decomposition of laumontite. Quartz remained after calcination and its diffraction peaks actually increased in intensity. Acid leaching was done to eliminate Fe from the shale as it competes with $\mathrm{Al}$ in the zeolite framework. The reduction in the orange-brown colour and Fe signal in EDAX, Fig. 2, confirm the removal of iron. Acid leaching also removed the remaining laumontite and caused a reduction in the peak intensity for quartz. The XRD pattern for $\mathrm{NaOH}$ fused shale confirms that quartz was removed completely by alkaline fusion and that sodium silicate and sodium aluminosilicate were the predominant phases remaining. These species are soluble in alkaline solution and provide the nutrients for the formation and eventual growth of zeolite crystals [3]. It is not possible to compare our findings directly with previous reports on the phases formed with shale (as opposed to kaolinite or fly-ash) after alkaline fusion, as no such results are reported [34-39]. However, it is well known that sodium silicate and sodium aluminosilicate are formed by the alkaline fusion of kaolinite, e.g. Belviso and Fiore have published widely on such preparations [15]. This finding, therefore, supports the formation of sodium silicate and sodium aluminosilicate in the present study, considering that kaolinite and shale have somewhat similar chemical compositions.

\subsection{Optimisation of zeolite preparation}


The next part of the study was to vary the experimental conditions in a systematic manner to find the parameters that give the highest quality zeolite (as measured by most intense XRD signal) from each experiment. The influence of water content was first determined, and its optimal value was then used in all further preparation methods. Next the stirring time was varied and its optimal value determined and used thereafter, and so on for aging time and hydrothermal treatment times at $100{ }^{\circ} \mathrm{C}$ in that order. The XRD patterns in Fig 3 show that the content of water has a profound effect on the degree of crystallinity. The zeolite was progressively favoured up to water:fused shale ratios of 8:1 and thereafter decreased sharply with only quartz present using a 15:1 ratio. For the sample prepared using ratio 8:1, the most intense diffraction peaks confirm the presence of faujasite (FAU) zeolite according to the International Zeolite Association (IZA) [40,41]. It makes sense that there is an optimum water to shale ratio, as the water content alters both the amount and alkalinity of solution that can dissolve reagents for nuclei formation and zeolite growth. To our knowledge, there are no reports showing the influence of the water to shale ratio in the preparation of zeolite. Hu et al. found that the ratio of water to sodium hydroxide had a profound effect on the crystals phases prepared from shale; the framework type of the product changed from cancrinite to hydroxysodalite sodalite when the water to $\mathrm{Na}_{2} \mathrm{O}$ ratio was decreased from 25:1 to 5:1 [38]. In the preparation of FAU-type zeolite from fly ash, the quantities of a dense sodium aluminium silicate phase and quartz were reduced when the water to alkaline fused fly ash ratio was increased from 4:1 to 10:1 [14].

Both the mixing and aging time (Figs. 4 and 5) experiments showed FAU zeolite was formed over the full range of chosen conditions showing that FAU- zeolite forms readily from shale but with large variations in crystal quality; the best conditions were $3 \mathrm{~h}$ mixing and $18 \mathrm{~h}$ aging time. Mixing/aging the suspension at RT allows the formation of nuclei that increase the eventual yield of zeolite. Fig 6 shows XRD patterns as a function of hydrothermal time; again there was variation over the chosen range, with the highest FAU purity formed after 24 hours. This finding matches well with $\mathrm{Hu}$ et al. who reported that the purity of hydroxysodalite prepared from shale increased with hydrothermal treatment time with the best zeolite formed after 24 hours (although longer times were not reported) [38]. Our findings also agree with that reported by Fernandes Machado et al. which showed that zeolite X peaked over the range 12$48 \mathrm{~h}$ at $100{ }^{\circ} \mathrm{C}$ and decreased substantially at longer times [39]. In the same synthesis, zeolites A and hydroysodalite peaked after $72 \mathrm{~h}$ and $96 \mathrm{~h}$, respectively. The results suggest that there is an evolution of crystal phases over time as follows: zeolite $\mathrm{X} \rightarrow$ zeolite $\mathrm{A} \rightarrow$ hydroxysodalite. 
Similar phase changes to progressively more stable structures were observed for mesoporous materials [42].

The results of water:shale ratio and mixing, aging and hydrothermal treatment times are quantified in Fig. 7 by plotting the $\mathrm{d}_{111}$ peak intensities. All four variables have a major influence on the FAU purity evidenced by the variation of peak intensity with changes in any given variable. The maximum peak intensities for each experiment confirm that the FAU zeolite with the highest intensity prepared by us (after optimising water:shale ratio and mixing, aging and hydrothermal treatment times) has comparable intensity to that of a commercial HY zeolite (dashed line). Overall, the results show that FAU zeolite can be prepared in pure form from shale rock using the method described here. This is a significant improvement on the procedure used by Fernandes Machado et al., which results in composite materials containing zeolites A, X and hydroxysodalite, all of which are contaminated by quartz [39]. Because of the large number of experimental variables (time, temperature, reagents) it is difficult to assign with certainty the exact cause(s) of the different results observed. While the general conditions of both syntheses are somewhat similar, the procedure used by Fernandes Machado et al. incorporated alumina and conducted alkaline fusion at $350^{\circ} \mathrm{C}$, while our method uses sodium silicate with alkaline fusion at $850{ }^{\circ} \mathrm{C}$ [39]. Unfortunately, no XRD results were provided to show the effect of alkaline fusion on the crystal phases present in shale, so based on the presence of quartz in all the final materials it is possible that quartz was not completely removed during the alkaline fusion step [39]. The variation may arise from the different minerals present: the shale contained illite, labradorite, quartz and chlorite, while our shale contains laumontite, quartz and chlorite. It is also interesting to note that the XRD patterns for the shale ash used in the syntheses of zeolites A [34,35] PI[37] and hydroxysodalite [38] showed that the relative amounts of quartz differed; for example the shale used to produce PI was reported to contain mainly feldspar while quartz was predominantly found in the shales used to prepare zeolite A and hydroxysodalite.

The total pore volume of the shale zeolite is $0.73 \mathrm{~cm}^{3} \mathrm{~g}^{-1}$ and BET surface area is $571 \mathrm{~m}^{2} \mathrm{~g}^{-1}$, which is $8.6 \%$ lower than that for commercial zeolite $\mathrm{Y}, 625 \mathrm{~m}^{2} \mathrm{~g}^{-1}$. This high surface area provides further proof that the FAU zeolite prepared here is of high purity. SEM images, Fig 8 , confirm the characteristic particle shape of FAU and agglomeration between particles in a similar manner to that of commercial zeolite Y. Fig. 8 also shows that the particle size for both 
samples was approximately $2 \mu \mathrm{m}$. The $\mathrm{Si} / \mathrm{Al}$ ratio of the shale zeolite was estimated to be 1.98 based on EDAX, Fig. 8, which is in the range for zeolite Y.

\subsection{Esterification reactions}

The esterification of oleic acid with ethanol is used as a test reaction to assess the catalytic activity of the shale zeolite. This is a reversible reaction so an excess quantity of ethanol, 6:1 ethanol/oleic acid molar ratio, is used to enhance conversion. The fractional conversions of oleic acid, Fig 9, increase, as expected, with reaction time at all temperatures but decreases slightly after 90 mins at $70{ }^{\circ} \mathrm{C}$. The conversion of oleic acid is highly dependent on reaction temperature where the maximum conversion increases from $45 \%$ at $40{ }^{\circ} \mathrm{C}$ to $78 \%$ at $70{ }^{\circ} \mathrm{C}$. This conversion compares well to that found in our previous study, which showed maximum oleic acid conversion of $85 \%$ for identical reaction conditions at $70{ }^{\circ} \mathrm{C}$ [27]. Fig. 10 shows that zeolite prepared from shale has almost identical conversions as that for the commercially sourced zeolite $\mathrm{Y}$, which strongly suggests that the shale zeolite has Bronsted acidity and catalytic properties practically identical to that of commercial zeolite $\mathrm{Y}$.

As with any esterification reaction, the formation of water prevents complete conversion of oleic acid by promoting the reverse reaction (hydrolysis) and driving the equilibrium to the left. Oleic acid conversions between 60 and >99\% were achieved for different montmorillonitebased clay catalysts by running the reaction at $150{ }^{\circ} \mathrm{C}$ for six hours, which removed the water produced during reaction by evaporation [43]. In another report, $>99 \%$ oleic acid conversion was found after 100 mins at $110{ }^{\circ} \mathrm{C}$ using sulfuric acid as catalyst whereby the water was removed using a zeolite A adsorption column [44]. However, the temperatures used in these methods also removes the ethanol required for esterification so is not ideal for real applications. There are relatively few reports showing zeolite catalysed oleic acid esterification reactions, and the majority use methanol where the following maximum conversion rates (of oleic acid) were recorded; $86 \%$ for zeolite beta $[45,46] ; 81 \%$ for mordenite, $80 \%$ for ZSM-5, and $78 \%$ for FAU-type zeolite [47]; and 83\% for ZSM-5 modified with citric acid [48]. For oleic acid esterification using ethanol, the maximum conversion over zeolite $\mathrm{NaY}$ was 27\% [49]; the high purity FAU-type zeolite prepared in this paper using shale shows significantly greater activity $(78 \%)$.

\section{Conclusions}

FAU-type zeolite was prepared from shale rock using a combination of acid leaching, alkaline fusion and hydrothermal treatment. The quality of the FAU was progressively improved 
through rigorous testing of the effects of preparation conditions on crystal purity. The FAUtype zeolite with the highest purity was active in the catalysed esterification of oleic acid, a model test reaction for biodiesel production, with conversions comparable to those of a commercially sourced zeolite Y.

\section{Acknowledgments}

ZTA is grateful to the Iraqi Ministry of Higher Education and Scientific Research for financial support to carry out this work at Manchester Metropolitan University, UK, as a part of the requirements for the degree of Doctor of Philosophy in Chemical Engineering at the University of Baghdad.

\section{References}

1. Hardy P. Fracking' in 'Issues in Environmental Science and Technology. R.E. Hester, R.M. Harrison, editors, Royal Society of Chemistry; 2015, 39, p. 1-45.

2. Weitkamp J. Zeolites and catalysis. Solid State Ionics 2000;131;175-188.

3. Cundy CS, Fox PA. The hydrothermal synthesis of zeolites: history and development from the earliest days to the present time. Chem. Rev. 2003;103;663-701.

4. Querol X, Moreno N, Umaña JC, Alastuey A, Hernández E, López-Soler A, Plana F. Synthesis of zeolites from coal fly ash: an overview. Int. J. Coal Geol. 2002;50;413-423.

5. Querol X, Umaña JC, Plana F, Alastuey A, López-Soler A, Medinaceli A, Valero A, Domingo MJ, Garcia-Rojo E. Synthesis of Na zeolites from fly ash in a pilot plant scale. Examples of potential environmental applications. Fuel 2001;80;857-865.

6. Norihiro M, Yamamoto H, Shibata J. Mechanism of zeolite synthesis from coal fly ash by alkali hydrothermal reaction. Int. J. Miner. Process. 2002;64;1-17.

7. Tanaka H, Matsumura S, Hino R. Formation process of Na-X zeolites from coal fly ash. J. Mater. Sci. 2004;39;1677-1682.

8. Wałek TT, Saito F, Zhang Q. The effect of low solid/liquid ratio on hydrothermal synthesis of zeolites from fly ash. Fuel 2008;87;3194-3199.

9. Tanaka H, Fujii A. Effect of stirring on the dissolution of coal fly ash and synthesis of pureform Na-A and -X zeolites by two-step process. Adv. Powder Technol. 2009;20;473-479. 
10. Gross-Lorgouilloux M, Gaullet P, Soulard M, Patarin J, Moleiro E, Saude I. Conversion of coal fly ashes into faujasite under soft temperature and pressure conditions. Mechanisms of crystallisation. Microporous Mesoporous Mater. 2010;131;407-417.

11. Shigemoto N, Hayashi H, Miyaura K. Selective formation of Na-X zeolite from coal fly ash by fusion with sodium hydroxide prior to hydrothermal reaction. J. Mater. Sci. $1992 ; 28 ; 4781-4786$.

12. Chang H.-L, Shih W.-H. A general method for the conversion of fly ash into zeolites as ion exchangers for cesium. Ind. Eng. Chem. Res. 1998;37;71-78.

13. Molina A, Poole C. A comparative study using two methods to produce zeolites from fly ash. Miner. Eng. 2004;17;167-173.

14. Tosheva L, Brockbank A, Mihailova B, Sutula J, Ludwig J, Potgieter H, Verran J. Micronand nanosized FAU-type zeolites from fly ash for antibacterial applications. J. Mater. Chem. 2012;22;16897-16905.

15. Belviso C, Cavalcante F, Lettino A, Fiore S. A and X-type zeolites synthesised from kaolinite at low temperature. Appl. Clay Sci. 2013;80-81;162-168.

16. Holmes SH, Alomair AA, Kovo AS. The direct synthesis of pure zeolite-A using 'virgin' kaolin. RSC Adv. 2012; 2;11491-11494.

17. Holmes SH, Khoo SH, Kovo AS. The direct conversion of impure natural kaolin into pure zeolite catalysts. Green Chem. 2011;13;1152-1154.

18. Kovo AS, Hernandez O, Holmes SH. Synthesis and characterization of zeolite Y and ZSM5 from Nigerian Ahoko kaolin using a novel, lower temperature, metakaolinization technique. J. Mater. Chem. 2009;19;6207-6212.

19. Shen B, Wang P, Yi Z, Zhang W, Tong X, Liu Y, Guo Q, Gao J, Xu C. Synthesis of zeolite $\beta$ from kaolin and its catalytic performance for FCC naphtha aromatization. Energy \& Fuels 2009;23;60-64.

20. Shen K, Qian W, Wang N, Zhang J, Wei F. Direct synthesis of c-axis oriented ZSM-5 nanoneedles from acid-treated kaolin clay. J. Mater. Chem. A 2013;1;3272-3275.

21. Caballero I, Colina FG, Costa J. Synthesis of X-type zeolite from dealuminated kaolin by reaction with sulfuric acid at high temperature. Ind. Eng. Chem. Res. 2007;46;1029-1038.

22. Wan G, Duan A, Zhang Y, Zhao Z, Jiang G, Zhang D, Gao Z, Liu J, Chung KH. Hydrodesulfurization of fluidized catalytic cracking diesel oil over NiW/AMB catalysts containing H-type $\beta$-zeolite in situ synthesized from kaolin material. Energy \& Fuels $2009 ; 23 ; 3846-3852$. 
23. de Lucas A, Uguina MA, Covian I, Rodriguez L. Use of Spanish natural clays as additional silica sources to synthesize 13X zeolite from kaolin. Ind. Eng. Chem. Res. 1993;32;1645-1650. 24. Murat M, Amokrane A, Bastide JP, Montanaro L. Synthesis of zeolites from thermally activated kaolinite. Some observations on nucleation and growth. Clay Minerals 1992;27;119130.

25. Johnson EBG, Arshad SE. Hydrothermally synthesized zeolites based on kaolinite: A review. Appl. Clay Sci. 2014;97-98;215-221.

26. Belviso C, Giannossa LC, Huertas FJ, Lettino A, Mangone A, Fiore S. Synthesis of zeolites at low temperatures in fly ash-kaolinite mixtures. Microporous Mesoporous Mater. $2015 ; 212 ; 35-47$.

27. Doyle AM, Albayati TM, Abbas AS, Alismaeel ZT. Biodiesel production by esterification of oleic acid over zeolite Y prepared from kaolin. Renewable Energy 2016;97;19-23.

28. Lee AF, Bennet JA, Manayil JC, Wilson K. Heterogeneous catalysis for sustainable biodiesel production via esterification and transesterification. Chem. Soc. Rev. 2014;43;78877916.

29. Su F, Guo Y. Advancements in solid acid catalysts for biodiesel production. Green Chem. 2014;16;2934-2957.

30. Lam MK, Lee KT, Mohamed AR. Homogeneous, heterogeneous and enzymatic catalysis for transesterification of high free fatty acid oil (waste cooking oil) to biodiesel: A review. Biotech. Adv. 2010;28;500-518.

31. Semwal S, Arora AK, Badoni RP, Tuli DK. Biodiesel production using heterogeneous catalysts. Bioresource Technol. 2011;102;2151-2161.

32. Borges ME, Diaz L. Recent developments on heterogeneous catalysts for biodiesel production by oil esterification and transesterification reactions: A review. Renew. Sust. Energy Rev. 2012;16;2839-2849.

33. Melero JA, Iglesias J, Morales G. Heterogeneous acid catalysts for biodiesel production: current status and future challenges. Green Chem. 2009;11;1285-1308.

34. Weiwei B, Lu L, Haifeng Z, Shucai G, Xuechun X, Guijuan J, Guimei G, Keyan Z. Removal of $\mathrm{Cu} 2+$ from aqueous solutions using Na-A zeolite from oil shale ash. Chinese J. Chem. Eng. 2013;21(9);974-982.

35. Weiwei B, Haifeng Z, Shucai G, Xuechun X, Guijuan J, Keyan Z. Adsorption of heavy metal ions from aqueous solutions by zeolite based on oil shale ash: Kinetic and equilibrium studies. Chem. Res. Chin. Univ. 2013;29(1);126-131. 
36. Shawabkeh R. Equilibrium study and kinetics of $\mathrm{Cu} 2+$ removal from water by zeolite prepared from oil shale ash. Process Safety Environmental Protection 2009;87;261-266.

37. Shawabkeh R, Al-Harahsheh A, Hami M, Khlaifat A. Conversion of oil shale ash into zeolite for cadmium and lead removal from wastewater. Fuel 2004;83;981-985.

38. Hu T, Qiu J, Wang Y, Wang C, Liu R, Meng C. Synthesis of low Si/Al ratio hydroxysodalite from oil shale ash without pretreatment. J. Chem. Technol. Biotechnol. 2015;90;208-212.

39. Fernandes Machado NRC, Miotto DMM. Synthesis of Na-A and -X zeolites from oil shale ash. Fuel 2005;84;2289-2294.

40. Parise JB, Corbin DR, Abrams L, Cox DE. Structure of dealuminated Linde Y-zeolite; $\mathrm{Si}_{139.7} \mathrm{Al}_{52.3} \mathrm{O}_{384}$ and $\mathrm{Si}_{173.1} \mathrm{Al}_{18.9} \mathrm{O}_{384}$ : presence of non-framework $\mathrm{Al}$ species. Acta. Cryst. 1984;C40;1493-1497.

41. Treacy MMJ, Higgins JB. Collection of simulated XRD powder patterns for zeolites. $4^{\text {th }}$ ed. Amsterdam; Elsevier; 2001.

42. Doyle AM, Ahmed E, Hodnett BK. The evolution of phases during the synthesis of the organically modified catalyst support MCM-48. Catal. Today 2006;116;50-55.

43. Neji BN, Trabelsi M, Frikha MH. Esterification of fatty acids with short-chain alcohols over commercial acid clays in a semi-continuous reactor. Energies 2009;2;1107-1117.

44. Lucena IL, Saboya RMA, Oliveira JFG, Rodrigues ML, Torres AEB, Cavalcante Jr CL, Parente Jr EJS, Silva GF, Fernandes FAN. Oleic acid esterification with ethanol under continuous water removal conditions. Fuel 2011;90;902-904.

45. Narkhede N, Patel A. Efficient synthesis of biodiesel over a recyclable catalyst comprising a monolacunary silicotungstate and zeolite H-beta. RSC Adv. 2014;4;64379-64387.

46. Narkhede N, Patel A. Biodiesel production by esterification of oleic acid and transesterification of soybean oil using a new solid acid catalyst comprising 12-tungstosilicic acid and zeolite H-beta. Ind. Eng. Chem. Res. 2013;52;13637-13644.

47. Chung K-H, Chang D-R, Park B-G. Removal of free fatty acid in waste frying oil by esterification with methanol on zeolite catalysts. Bioresource Technol. 2008;99;7438-7443.

48. Vieira SS, Magriotis ZM, Ribeiro MF, Graça I, Fernandes, Lopes JMFM, Coelho SM, Santos NAV, Saczk AA. Use of HZSM-5 modified with citric acid as acid heterogeneous catalyst for biodiesel production via esterification of oleic acid. Microporous Mesoporous Mater. 2015;201;160-168.

49. Marchetti JM, Errazu AF. Comparison of different heterogeneous catalysts and different alcohols for the esterification reaction of oleic acid. Fuel 2008;87;3477-3480. 